\title{
Propagação vegetativa de Juniperus chinensis
}

\author{
Rosimeri de Oliveira Fragoso*, Katia Christina Zuffellato-Ribas, Gustavo Macanhão, \\ Carlos André Stuepp, Henrique Soares Koehler
}

Universidade Federal do Paraná, Curitiba, PR, Brasil

*Autor correspondente, e-mail: meri_ol@yahoo.com.br

\section{Resumo}

Juniperus chinensis L. var. kaizuka pertencente à família Cupressaceae e conhecido como kaizuka, é uma espécie bastante utilizada no paisagismo, diferenciando-se de outras variedades da espécie principalmente pelo seu hábito de crescimento tortuoso. A reprodução sexuada de Juniperus chinensis apresenta desvantagens e sua propagação por estaquia poderia facilitar a obtenção de mudas. Dessa forma, objetivou-se avaliar o efeito de três diferentes concentrações da auxina sintética ácido indolbutírico (0, 1500 e $\left.3000 \mathrm{mg} \mathrm{L}^{-1}\right)$ na promoção do enraizamento de estacas caulinares de Juniperus chinensis var. kaizuka, coletadas nos terços basal $(0,5 \mathrm{~m}$ a 2,0 m), mediano $(2,1 \mathrm{~m}$ a $3,5 \mathrm{~m})$ e apical $(3,6 \mathrm{~m}$ a $5,0 \mathrm{~m})$ das plantas matrizes e nas estações de inverno, primavera e outono de 2012, visando subsidiar a elaboração de um protocolo de propagação da espécie. Após 140 dias em casa de vegetação, verificou-se que a escolha adequada da época para coleta das estacas é essencial à viabilidade da técnica de propagação vegetativa de Juniperus chinensis var. kaizuka, com a recomendação da estação de primavera como mais adequada para promoção do enraizamento. Contudo, embora a aplicação de AIB e altura de coleta na planta matriz tenham apresentado efeitos significativos para algumas variáveis, não se observou em relação a esses fatores um padrão que apresentasse maior indução do sistema radicial da espécie.

Palavras-chave: auxina, enraizamento, estação do ano, gradiente de juvenilidade, teoria do cone

\section{Vegetative propagation of Juniperus chinensis}

\begin{abstract}
Juniperus chinensis L. var. kaizuka, belonging to the Cupressaceae family and known as kaizuka is a species widely used in landscaping, being different from the other varieties of the species mainly because of its tortuous growth habits. The sexual reproduction of Juniperus chinensis has disadvantages and its propagation by cuttings can facilitate the production of seedlings. Thus, this study aimed to evaluate the effect of three different concentrations of the synthetic auxin indolebutyric acid $(0$, 1500 and $3000 \mathrm{mg} \mathrm{L}^{-1}$ ) to promote rooting of Juniperus chinensis var. kaizuka, collected in the basal $(0.5$ to $2.0 \mathrm{~m})$, middle $(2.1$ to $3.5 \mathrm{~m})$ and apical $(3.6$ to $5.0 \mathrm{~m})$ portions of the stock plant, during winter, spring and autumn of 2012, with the intent to subsidize the development of a propagation protocol for the species. After 140 days in the greenhouse, it was observed that choosing the proper season to collect cuttings is essential for the viability of vegetative propagation technique for Juniperus chinensis var. kaizuka, with the recommendation of spring as the more suitable season for rooting development. However, although the application of AIB and the collection height in the stock plant have shown significant effects on some variables, it wasn't observed a standard, related to these factors, producing a greater induction of the radicial system of the species.
\end{abstract}

Keywords: auxin, rooting, season, gradient of juvenility, cone of juvenility 


\section{Introdução}

O gênero Juniperus, pertencente à família Cupressaceae, compreende diversas espécies, dentre elas Juniperus chinensis L., que por sua vez, contém dezenas de variedades (Adams, 2014). Juniperus chinensis var. kaizuka Hort. ex Endl., popularmente conhecido como kaizuka, é uma espécie de origem asiática, de hábito arbóreo ou arbustivo, normalmente com bifurcações ao longo do tronco tortuoso, podendo atingir até $7 \mathrm{~m}$ de altura. Apresenta folhas perenes, em escamas, verde-escuras e com odor característico. As inflorescências são discretas e dão origem a pequenos frutos globosos (Lorenzi, 2003).

Diferencia-se das outras variedades pelo hábito de crescimento tortuoso, copa irregular e feixes de ramos longos nas extremidades, características que garantem seu grande potencial paisagístico (Lorenzi, 2003). Além do uso como planta ornamental, é comumente utilizada na medicina oriental, devido a propriedades medicinais dos seus frutos e folhas (Ju et al., 2008).

A reprodução sexuada da espécie apresenta algumas desvantagens, tais como o longo período de amadurecimento dos frutos, necessidade de tratamentos para quebra de dormência das sementes, baixo índice de germinação e dificuldade na obtenção de sementes viáveis (Adams, 2014). Em virtude de tais dificuldades, a propagação por estaquia poderia ser uma opção viável devido a maior facilidade de reprodução das espécies (Khoushnevis et al., 2008; Oliveira \& Ribeiro, 2013).

A propagação vegetativa consiste na regeneração e multiplicação de mudas a partir de partes destacadas da planta matriz, permitindo a obtenção de indivíduos idênticos (Hartmann et al., 2011). Por meio desse método é possível aumentar a produção em um menor período de tempo (Stuepp et al., 2013), selecionar genótipos de interesse e produzir populações uniformes com maior controle das fases de desenvolvimento (Hartmann et al., 2011).

A estaquia é caracterizada pela indução da rizogênese das estacas, sendo necessários níveis adequados de auxinas endógenas, as quais nem sempre se encontram em concentrações satisfatórias na planta (Osterc \& Štampar, 2011).

Influências ambientais, tais como temperatura, pluviosidade e fotoperíodo podem atuar sobre os níveis endógenos de auxina de plantas matrizes submetidas às variações sazonais, influenciando o enraizamento das estacas (Kibbler et al., 2004). Esse efeito é diferente em função da espécie, podendo ser necessária a adição de auxinas sintéticas com o intuito de aumentar a capacidade de enraizamento em algumas plantas. A adição de auxinas tem sido verificada em muitos trabalhos, os quais demonstram diferentes resultados para cada espécie (Abu-Zahra et al., 2013).

Domesmo modo, a maturação fisiológica em plantas lenhosas pode afetar a capacidade de propagação vegetativa (Wendling et al., 2014a), conforme sugerido pela Teoria do Cone. Essa teoria se sustenta na ideia de que quanto maior o grau de maturação fisiológica, menor a capacidade de enraizamento das estacas (Wendling et al., 2014b).

Desta forma, objetivou-se avaliar o efeito de diferentes concentrações da auxina sintética ácido indolbutírico (AIB) na promoção do enraizamento de estacas caulinares de Juniperus chinensis L. var. kaizuka, coletadas em três regiões das plantas matrizes e em três épocas de coleta.

\section{Material e Métodos}

Para a realização do experimento foram coletados ramos provenientes de seis matrizes de Juniperus chinensis var. kaizuka com 15 anos de idade e $5 \mathrm{~m}$ de altura, plantadas a pleno sol, localizadas no município de Curitiba (PR) (254' S e 49²3' W, 920 m). Segundo a classificação de Koppen, o clima da região é temperado, do tipo Cfb, com temperatura média em torno de 17 ${ }^{\circ} \mathrm{C}$, sendo a máxima de $23^{\circ} \mathrm{C}$ e a mínima de 13 ${ }^{\circ} \mathrm{C}$, permanecendo as temperaturas baixas até meados da primavera.

Os ramos foram coletados com tesoura de poda e imediatamente após a coleta, foram umedecidos com água e acondicionados em sacos plásticos e transportados para o local do experimento. O experimento foi conduzido em casa de vegetação climatizada, com 
temperatura média de $24^{\circ} \mathrm{C} \pm 2{ }^{\circ} \mathrm{C}$ e $85 \%$ de umidade relativa do ar, localizada no Campus III do Centro Politécnico pertencente à Universidade Federal do Paraná, Curitiba - PR.

A coleta dos ramos para a confecção das estacas ocorreu no inverno, primavera e outono. Para a definição das alturas de coleta nas plantas matrizes considerou-se a altura total destas dividida por três (Stuepp et al., 2013; Wendling et al., 2014a). Dessa forma, as coletas foram realizadas em três intervalos de altura nas plantas matrizes a partir da região do colo: 0,5 m a 2,0 m (basal) , 2,1 m a 3,5 m (mediana) e 3,6 a $5 \mathrm{~m}$ (apical). Dentro de cada intervalo de altura, nas porções medianas de cada ramo, foram retiradas estacas para a propagação.

Foram confeccionadas estacas caulinares semilenhosas com 6 a $8 \mathrm{~cm}$ de comprimento, com corte em bisel na base e reto no ápice. Após o preparo, foi removido cerca de um terço das folhas da porção basal da estaca. As estacas receberam tratamento fitossanitário com hipoclorito de sódio a 0,5\% durante 10 minutos, sendo posteriormente lavadas em água corrente por 10 minutos (Ferriani et al., 2007; Stuepp et al., 2014).

Logo em seguida, a base das estacas foi tratada com ácido indolbutírico por 10 segundos de imersão, nas concentrações de 0, 1500 e 3000 $\mathrm{mg} \mathrm{L}^{-1}$ (solução hidroalcóolica 1:1 v/v, diluindo o AIB em álcool 98\%, completando-se o volume com água de acordo com a concentração). As estacas do tratamento testemunha $\left(0 \mathrm{mg} \mathrm{L}^{-1}\right)$ foram imersas em solução de água destilada e álcool 98\% (1:1 v/v). O estaqueamento foi realizado em tubetes de polipropileno com $53 \mathrm{~cm}^{3}$, preenchidos com substrato a base de vermiculita de granulometria fina e casca de arroz carbonizada (1:1 em v/v).

Após 140 dias em casa de vegetação (Stuepp et al., 2014), as estacas foram removidas dos tubetes e lavadas em água para as avaliações. Foram avaliadas as seguintes variáveis: porcentagem de estacas enraizadas (estacas vivas que apresentavam raízes de pelo menos $2 \mathrm{~mm}$ de comprimento); número de raízes por estaca (contagem do número de raízes primárias); comprimento das três maiores raízes por estaca $(\mathrm{cm})$; porcentagem de estacas com calos (estacas vivas, sem raízes, com formação de massa de células indiferenciadas na base); porcentagem de sobrevivência (estacas vivas, sem a formação de raízes ou calos) e porcentagem de mortalidade (estacas com tecidos necrosados).

O delineamento experimental adotado foi o inteiramente casualizado, com arranjo fatorial $3 \times 3 \times 3$, correspondente a três alturas de coleta das estacas na planta matriz (basais, medianas e apicais), três concentrações de AIB (0, 1500 e $3000 \mathrm{mg} \mathrm{L}^{-1}$ ) e três épocas de coleta (inverno, primavera e outono), com quatro repetições de 20 estacas por unidade experimental, totalizando 2.160 estacas. Os dados foram avaliados quanto à homogeneidade pelo teste de Bartlett, e as médias comparadas pelo teste de Tukey ao nível de $5 \%$ de probabilidade.

\section{Resultados e Discussão}

Não foi observada interação tripla significativa entre os fatores época de coleta, altura de coleta das estacas e concentração de AIB aplicada. Contudo, quando as épocas de coleta foram analisadas separadamente, verificaram-se diferenças significativas entre elas.

Demaneira geral, oinverno correspondeu ao período com os resultados menos satisfatórios para enraizamento das estacas (1,25\%), formação de calos (15,83\%) (Figura 1), número (0,19 raízes) e comprimento de raízes por estaca $(0,26 \mathrm{~cm})$, diferindo estatisticamente das demais estações (Tabela 1).

Essas diferenças obtidas em relação às épocas de coletas do material podem ocorrer por vários fatores que influenciam os níveis endógenos de auxina, como estádio fenológico em que as matrizes se encontravam no momento da coleta (Wendling et al., 2014a), grau de lignificação devido às concentrações de enzimas lignificantes (Ferriani et al., 2007) e equilíbrio hormonal em função das taxas metabólicas (Osterc \& Štampar, 2011).

Resultados significativamente reduzidos para o inverno têm sido também encontrados em outros trabalhos de propagação por estaquia, mesmo quando aplicados reguladores vegetais (Alcantara et al., 2008). Isso é associado ao fato de que, nessa época, plantas lenhosas 


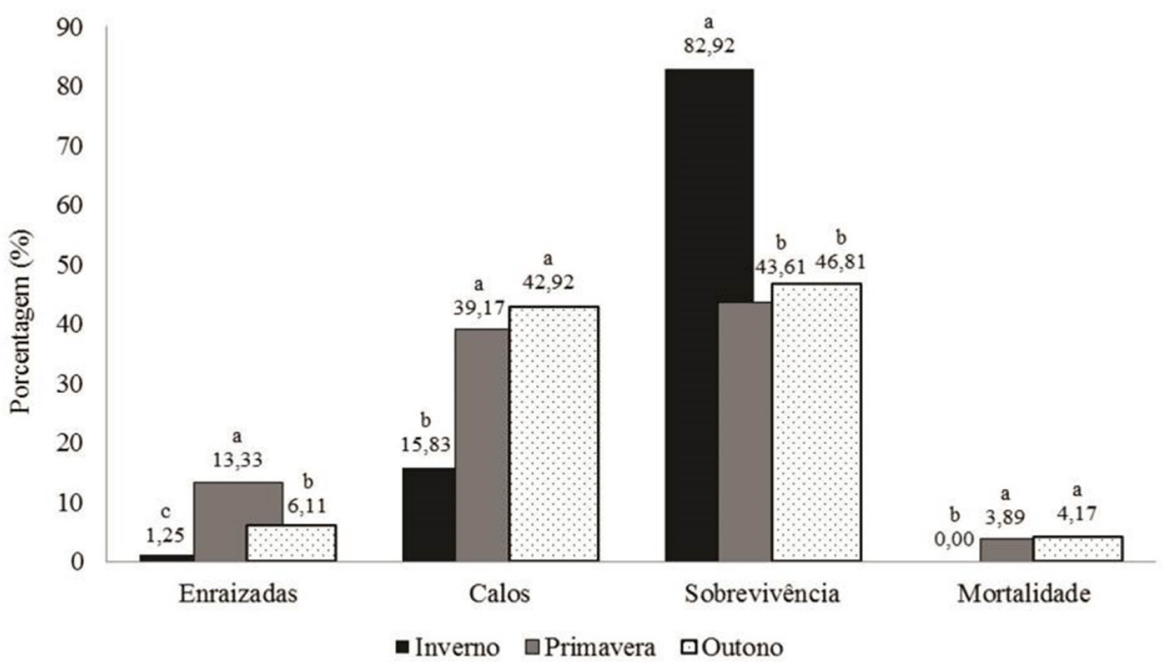

Figura 1. Médias gerais das porcentagens de enraizamento, formação de calos, sobrevivência e mortalidade em estacas de Juniperus chinensis var. kaizuka coletadas nas estações de inverno, outono e primavera. Médias seguidas pela mesma letra em cada variável não diferem entre si pelo Teste de Tukey a 5\% de probabilidade.

Tabela 1. Médias gerais das porcentagens de enraizamento, número de raízes por estaca e comprimento das três maiores raízes por estaca em estacas de Juniperus chinensis var. kaizuka coletadas nas estações de inverno, primavera e outono.

\begin{tabular}{cccc}
\hline Estação & Enraizamento (\%) & $N^{\circ}$ de raízes/estaca & Comprimento raízes/estaca $(\mathrm{cm})$ \\
\hline Inverno & $1,25 \mathrm{c}$ & $0,19 \mathrm{c}$ & $0,26 \mathrm{c}$ \\
Primavera & $13,33 \mathrm{a}$ & $1,90 \mathrm{a}$ & $4,81 \mathrm{a}$ \\
Outono & $6,11 \mathrm{~b}$ & $1,20 \mathrm{~b}$ & $2,64 \mathrm{~b}$ \\
\hline
\end{tabular}

estão em estado de dormência para proteger seus meristemas das baixas temperaturas, com redução das atividades nos tecidos jovens do floema secundário, dos raios vasculares e do câmbio e em contrapartida, com aumento das concentrações de compostos fenólicos e inibidores, cessando temporariamente seu crescimento (Ferriani et al., 2007).

Além disso, há maior lignificação dos ramos devido ao aumento de enzimas peroxidases, as quais são também responsáveis pela degradação de auxinas (Tehranifar et al., 2014). Essa redução é frequentemente verificada em espécies perenes de clima temperado, como J. chinensis, nas quais os teores de auxinas são muito baixos no período de inverno, sendo por isso apontado como um dos fatores que contribuem para os menores percentuais de enraizamento (Ferriani et al., 2007).

Apesar disso, a mortalidade foi nula nesse período e a porcentagem de sobrevivência foi significativamente superior, com cerca de $80 \%$ de estacas vivas (Figura 1), indicando que estas foram mantidas por meio de suas reservas e que um período maior em casa de vegetação talvez resultasse em um aumento nos percentuais de estacas enraizadas (Stuepp et al., 2014).

No outono, alguns efeitos relatados no inverno sobre as plantas, as quais estão se preparando para entrar em dormência, têm sido constatados em vários trabalhos (Paula et al., 2009; Marangon et al., 2013). Segundo alguns autores, os dias curtos associados as baixas temperaturas exercem influência negativa nos processos de translocação de compostos e fotossíntese devido à inibição do ingresso de fosfatos nos cloroplastos das árvores matrizes, dificultando $\circ$ enraizamento do material coletado nessas estações (Lawson et al., 2012).

Por outro lado, na primavera observaram-se os maiores resultados para enraizamento, número e comprimento de raízes por estaca, diferindo estatisticamente das demais estações (Tabela 1). Alguns estudos com coníferas (Ragonezi et al., 2010; Alcantara et al., 2008) e também com outras plantas (Paula, 2009) apontam que na primavera as plantas matrizes encontram-se em período de crescimento vegetativo intenso, e por isso estacas coletadas nesse momento são com 
frequência mais herbáceas, com elevada atividade cambial e produção de auxinas, carboidratos e cofatores do enraizamento, como substâncias nitrogenadas e compostos fenólicos, atribuindo a esses fatores os maiores percentuais de enraizamento obtidos.

Segundo alguns autores (Trevisan et al., 2008; Marangon et al., 2013), isso é possível devido às condições ambientais favoráveis como elevada precipitação, temperatura e radiação, as quais interferem diretamente sobre o crescimento e desenvolvimento das plantas por meio da fotossíntese, modulação do fotoperíodo e da qualidade da luz.

Contudo, os efeitos da quantidade e qualidade de Luz correspondente a cada época do ano são variáveis entre as espécies de coníferas, podendo suprimir ou aumentar os percentuais de enraizamento. Em estudo prévio realizado com espécies ornamentais do gênero Juniperus (Kunneman \& Ruesink, 1997), os autores observaram que estacas submetidas a uma alta intensidade luminosa apresentavam um percentual de enraizamento superior àquelas submetidas à baixa intensidade luminosa. Da mesma forma, estacas de Pinus elliottii var. elliottii Engelm (Hare, 1978) obtidas a partir de ramos coletados no verão e primavera, sob dias longos, apresentaram enraizamento superior aos ramos coletados no período de inverno, semelhante ao observado no presente trabalho.

Para algumas espécies, entretanto, esses resultados não se confirmam, como por exemplo, no trabalho com a espécie Pinus sylvestris (Ernstsen, 1982) no qual os maiores percentuais de enraizamento e número de raízes foram obtidos nas estações de outono e inverno durante um menor fotoperíodo. Tais resultados evidenciam a importância de estudos em diferentes épocas do ano para cada espécie.

Em relação aos fatores altura de coleta e concentração de AIB nas três estações, não houve interação significativa para nenhuma das variáveis, demonstrando que tais fatores são independentes. No período de inverno, da mesma forma, não foram observadas diferenças significativas mesmo quando esses fatores foram analisados separadamente.

No outono e primavera por outro lado, os fatores altura de coleta e concentração de AIB apresentaram diferenças significativas para algumas variáveis (Figura 2).

Para a formação de raízes no outono, os maiores valores foram 9,58\% de enraizamento, 1,56 raízes por estaca e $3,55 \mathrm{~cm}$ a média do comprimento das três maiores raízes por estaca, na primavera os maiores valores para essas variáveis foram 18,75\%, 2,60 raízes/estaca e 6,54 $\mathrm{cm}$, respectivamente (Tabela 2 ).

Observam-se de modo geral, baixos valores para a formação de raízes em todos os tratamentos, independente da época de coleta. Os maiores percentuais foram observados para as variáveis formação de calos e sobrevivência de estacas. Como o tempo de resposta para a formação de raízes em cada espécie pode variar de poucos dias (Maia et al., 2008) até alguns meses (Alcantara et al., 2007), os maiores percentuais de formação de calos e sobrevivência poderiam indicar que as condições ambientais às quais as estacas foram mantidas, resultariam no aumento do percentual de enraizamento, se a permanência das mesmas em casa de vegetação ocorresse por um período maior (Oliveira \& Ribeiro, 2013). Entretanto, apesar da casa de vegetação ter apresentado condições adequadas para a manutenção prolongada das estacas, não é possível garantir que as estacas vivas enraizariam, pois já estavam há 140 dias no leito de enraizamento.

Por outro lado, a presença de calos pode indicar também a baixa juvenilidade do material (Hartmann et al., 2011), tendo em vista que a coleta foi realizada em plantas adultas de var. kaizuka, com cerca de 15 anos de idade. Dessa forma, novos experimentos utilizando técnicas de rejuvenescimento do material poderiam levar a resultados diferentes para 0 enraizamento dessa espécie (Wendling et al., 2014b).

Apesar disso, os resultados obtidos no presente trabalho podem ser considerados promissores para fins de resgate de matrizes com caracteres de interesse, quando se considera que J. chinensis var. kaizuka tem sido caracterizada, nos poucos trabalhos existentes, como uma espécie de difícil propagação assexuada. Os valores de enraizamento, frequentemente muito 
Posição de coleta nas plantas matrizes Outono

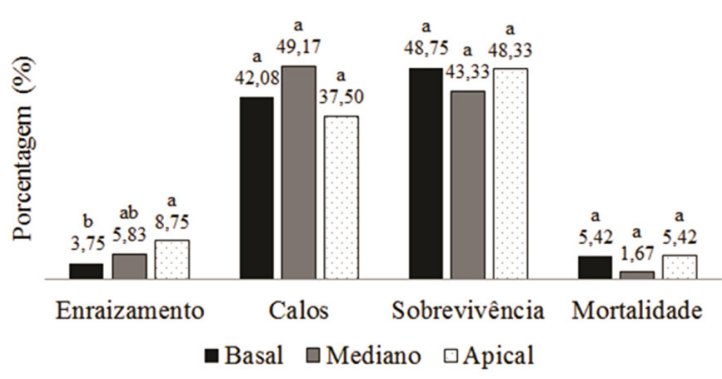

Posição de coleta nas plantas matrizes Primavera

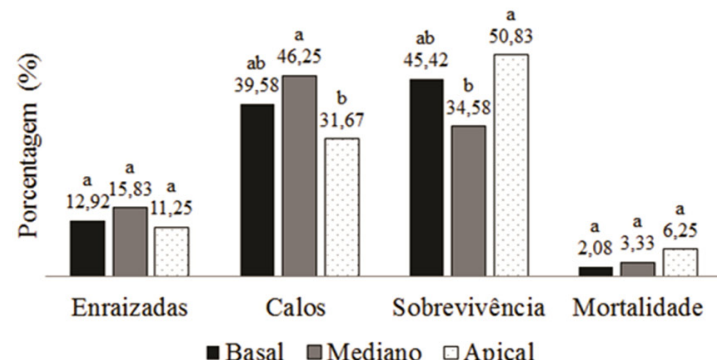

Concentrações de AIB

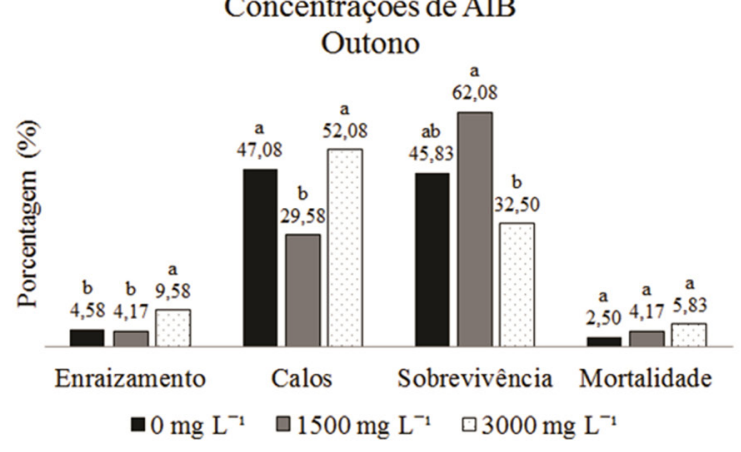

Concentrações de AIB Primavera

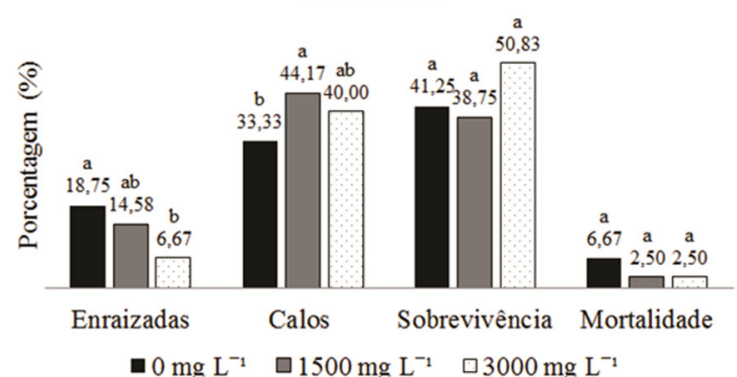

Figura 2. Médias das porcentagens de enraizamento, formação de calos, sobrevivência e mortalidade em estacas de J. chinensis var. kaizuka, submetidas a diferentes alturas de coleta e concentrações de AlB nas estações de outono e primavera. Médias seguidas pela mesma letra em cada variável não diferem entre si pelo Teste de Tukey a 5\% de probabilidade.

Tabela 2. Médias das porcentagens de enraizamento, número de raízes/estaca e comprimento das três maiores raízes/estaca em estacas de J. chinensis var. kaizuka, submetidas a diferentes alturas de coleta e concentrações de AIB nas estações de outono e primavera.

\begin{tabular}{|c|c|c|c|c|c|c|}
\hline & Posição & $\begin{array}{c}\text { No de raízes/ } \\
\text { estaca }\end{array}$ & $\begin{array}{l}\text { Comprimento } \\
\text { raízes/estaca }(\mathrm{cm})\end{array}$ & $\operatorname{AIB}\left(\mathrm{mg} \mathrm{L}^{-1}\right)$ & $\begin{array}{c}\text { No de raízes/ } \\
\text { estaca }\end{array}$ & $\begin{array}{c}\text { Comprimento raízes/ } \\
\text { estaca }(\mathrm{cm})\end{array}$ \\
\hline \multirow{3}{*}{ 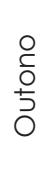 } & Basal & $0,79 a$ & $2,63 a$ & 0 & $0,96 a$ & $3,05 a$ \\
\hline & Mediano & $1,25 a$ & $1,74 a$ & 1500 & $1,29 \mathrm{a}$ & $2,76 a$ \\
\hline & Apical & $1,56 a$ & $3,55 a$ & 3000 & $1,35 a$ & $2,11 \mathrm{a}$ \\
\hline \multirow{3}{*}{ 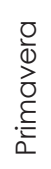 } & Basal & $2,21 \mathrm{a}$ & $4,47 a$ & 0 & $2,60 a$ & $6,54 a$ \\
\hline & Mediano & $1,77 \mathrm{a}$ & $5,14 a$ & 1500 & $1,97 \mathrm{ab}$ & $6,24 a$ \\
\hline & Apical & $1,73 a$ & $4,81 a$ & 3000 & $1,14 \mathrm{~b}$ & $1,64 \mathrm{~b}$ \\
\hline
\end{tabular}

baixos, denotam a necessidade de mais estudos sobre a espécie a fim de estabelecer protocolos efetivos para sua propagação.

Resultados semelhantes foram obtidos em um trabalho com Pinus taeda L. (Alcantara et al., 2008), no qual os autores verificaram baixos percentuais de enraizamento para a espécie apesar da aplicação de AIB. De acordo com os autores, a limitação ao processo de rizogênese das estacas estaria possivelmente ligado a presença de inibidores do enraizamento, a existência de poucos grupos de células responsivas a auxina e ausência de sítios receptores específicos.

Em relação a variável altura de coleta das estacas, visando verificar a existência de um gradiente de juvenilidade em direção a base da árvore, não foi observado um padrão que apontasse alguma posição de coleta como de menor maturidade e maior capacidade rizogênica. No outono apenas a variável enraizamento apresentou diferença significativa 
entre as três alturas de coleta, sendo a posição apical a com maior percentual de enraizamento nesta estação (8,75\%) (Figura 2).

$\mathrm{Na}$ primavera houve diferença significativa para as variáveis formação de calos $(46,25 \%)$ e sobrevivência $(50,83 \%)$, nas porções mediana e apical da planta matriz, respectivamente. Em outro trabalho com J. chinensis var. kaizuka (Stuepp et al., 2014), buscando relacionar sua capacidade rizogênica com altura de coleta (16\%), os autores obtiveram também maiores percentuais de enraizamento em estacas coletadas na porção apical da planta, apontando que tal resultado poderia estar relacionado ao fato dos ramos das porções apicais serem menos lignificados, e com isso possuírem maior quantidade de células meristemáticas e um metabolismo mais ativo.

Essa resposta é frequente em estacas semilenhosas, as quais correspondem ao tipo de material vegetal utilizado neste trabalho. Resultados semelhantes foram observados para a espécie Pinus radiata (Corrêa et al., 2015), a qual apresentou maiores percentuais de enraizamento para estacas coletadas nas porções apicais e medianas das plantas matrizes, quando em comparação às estacas da região basal. Estacas coletadas da porção apical tendem a apresentar maiores percentuais de enraizamento, o que pode ser atribuído a uma maior proximidade dos sítios de síntese de auxinas e maior concentração de promotores da rizogênese (Wendling et al., 2014b).

Tais resultados discordam da Teoria do Cone, que pressupõe a existência de um aumento da maturação em função da maior proximidade com o meristema apical. De acordo com essa teoria, meristemas formados em épocas mais próximas à germinação, como da região basal, apresentariam maior juvenilidade do que o das regiões terminais (Wendling et al., 2014a).

O decréscimo do enraizamento em direção ao meristema apical, proposto pela Teoria do Cone, está possivelmente relacionado às características bioquímicas e anatômicas, as quais se modificam ao longo do desenvolvimento da planta (Wendling et al., 2014a). A transição da alta para a baixa capacidade de enraizamento pode estar atrelada à redução da concentração endógena de hormônios vegetais (Osterc \& Štampar, 2011), requerendo a aplicação exógena de auxinas sintéticas, a fim de promover um balanço hormonal adequado que favoreça o enraizamento das estacas.

Negash (2002) trabalhando com estacas provenientes de plantas matrizes de Juniperus procera em diferentes graus de maturação associou-os a aplicação de diferentes concentrações de AIB, verificando que quanto maior o estado de maturação, maior a concentração de AIB necessária para alcançar os mesmos percentuais de enraizamento. Além disso, observou que o enraizamento em estacas menos juvenis ocorria independente da formação de calos, e que nas estacas mais juvenis, cerca de $95 \%$ destas apresentaram formação de calo.

Contudo, mesmo a aplicação de reguladores vegetais está sujeita as condições fisiológicas e genéticas da planta matriz (Kibbler et al., 2004), podendo não resultar em um aumento significativo de enraizamento, assim como foi observado no presente trabalho. Alcantara et al. (2008) trabalhando com Pinus taeda verificaram que a utilização de AIB causou redução na porcentagem de enraizamento para todas as épocas de coleta das brotações. Os autores sugerem que o requerimento de auxina exógena não se faz necessário ao enraizamento de P. taeda, possivelmente pelo fato de que a habilidade em formar raízes adventícias está mais relacionada com a competência das células a iniciar divisões celulares em resposta à auxina, do que com a limitação do nível endógeno.

No outono, em função das prováveis menores concentrações endógenas de auxinas frequentemente encontradas, a aplicação de $3000 \mathrm{mg} \mathrm{L}^{-1}$, maior concentração utilizada, foi a que apresentou maior enraizamento (9,58\%), diferindo estatisticamente das demais concentrações. Já as variáveis, número de raízes/estaca e comprimento médio das três maiores raízes não apresentaram diferenças significativas.

$\mathrm{Na}$ primavera, por outro lado, a concentração de $3000 \mathrm{mg} \mathrm{L}^{-1}$ proporcionou - menor percentual de enraizamento 
(6,67\%), sendo a concentração controle de $0 \mathrm{mg} \mathrm{L}^{-1}$ a que resultou no maior percentual $(18,75 \%)$. Isso pode estar relacionado ao fato do estímulo à indução radicial, provocado pelo aumento da concentração de auxina exógena, ter ultrapassado seu ponto máximo a partir do qual se torna inibitório (Pop et al., 2011). Isso é possível quando se considera que na primavera a planta possui níveis mais altos de auxinas endógenas, as quais estariam se somando, nesse caso, a auxina sintética aplicada, elevando sua concentração interna a níveis inibitórios para o enraizamento.

Pesquisas envolvendo outros fatores como uso de luz artificial, aquecimento do leito de enraizamento e uso de diferentes substratos, contudo, em função do maior controle sobre a qualidade do ambiente, podem apresentar resultados diferentes. Em um trabalho desenvolvido com a espécie Juniperus polycarpos (Khoushnevis et al., 2008), os autores associaram a aplicação de concentrações de AIB, com variados substratos e tipos de luzes e obtiveram efeitos significativos para essas variáveis, alcançando um enraizamento de quase $40 \%$ das estacas tratadas com $2500 \mathrm{mg}$ $\mathrm{L}^{-1}$ sob luz branca e plantadas em solo de textura macia.

Ainda para esse gênero, em pesquisa com Juniperus excelsa, utilizando uma mistura de turfa e fibra de coco como substrato, foram encontradas diferenças significativas entre diferentes concentrações de AIB, apontando que, das concentrações aplicadas, houve um decréscimo do enraizamento a partir da concentração de $4000 \mathrm{mg} \mathrm{L}^{-1}$ a $6000 \mathrm{mg} \mathrm{L}^{-1}$ (Esmaeilnia et al., 2006).

Outros trabalhos com o gênero Juniperus têm apontado como relevante para promoção do enraizamento e formação de calos, fatores como tamanho das estacas, tipo de luz, substrato e condições de umidade do ar na casa de vegetação, ainda que os resultados sejam variados, necessitando dessa forma de pesquisas mais específicas (Khoushnevis et al., 2008; Ahani et al., 2013).

\section{Conclusões}

Nas condições em que o presente trabalho foi executado, é recomendada a estação de primavera como mais adequada para promoção do enraizamento em Juniperus chinensis var. kaizuka.

Apesar dos efeitos significativos para algumas variáveis, não se observa um padrão ao longo das estações em relação à aplicação de AIB e posições de coleta na planta matriz, que apresente maior indução do sistema radicial para essa espécie.

\section{Agradecimentos}

Ao Grupo de Estudo e Pesquisa em Estaquia (GEPE) da Universidade Federal do Paraná.

À Floricultura e Garden Center Ópera Garden pela disponibilização das plantas matrizes para realização da pesquisa.

\section{Referências}

Abu-Zahra, T.R., Al-Shadaideh, A.N., Abubaker, S.M., Qrunileh, I.M. 2013. In $\square$ vence of auxin concentrations on different ornamental plants rooting. International Journal of Botany 9: 96-99.

Adams, R.P. 2014. Junipers of the world: the genus Juniperus. Trafford Publishing, Bloomington, USA. $422 \mathrm{p}$.

Ahani, H., Jalilvand, H., Nasr, S.M.H., Kouhbanani, H.S., Ghazi, M.R., Mohammadzadeh, H. 2013. Reproduction of juniper (Juniperus polycarpos) in Khorasan Razavi, Iran. Forest Science and Practice 15: 231-237.

Alcantara, G.B., Ribas, L.L.F., Higa, A.R., ZuffellatoRibas, K.C., Koehler, H.S. 2007. Efeito da idade da muda e da estação do ano no enraizamento de miniestacas de Pinus taeda L. Revista Árvore 31: 399-404.

Alcantara, G.B., Ribas, L.L.F., Higa, A.R., ZuffellatoRibas, K.C. 2008. Efeitos do ácido indolbutírico (AIB) e da coleta de brotações em diferentes estações do ano no enraizamento de miniestacas de Pinus taeda L. Scientia Forestalis 36: 151-156.

Corrêa, P.R.R., Schultz, B., Aver, C.G., Higa, A.R. 2015. Efeito da planta matriz, estação do ano e ambiente de cultivo na miniestaquia de Pinus radiata. Floresta 45: 65-74.

Ernstsen, J.H.A. 1982. Seasonal changes in adventitious root formation in hypocotyl cuttings of Pinus sylvestris: influence of photoperiod during 
stock plant growth and of indolebutyric acid treatment of cuttings. Physiologia Plantarum 54: 99-106.

Esmaeilnia, M., Jalali, S.GH.A., Tabari, M., Hosseini, S.M. 2006. Influence of plant growth regulator IBA on vegetative propagation of Juniperus excelsa. Iranian Journal of Forest and Poplar Research 14: 221-227.

Ferriani, A., Borges, M., ZuffellatO-Ribas, K.C., Carpanezzi, A., Koehler, H. 2007. Influência da época do ano e das diferentes formas de aplicação de ácido naftaleno acético (ANA) no enraizamento de Mikania micrantha Kunth. Revista Brasileira de Plantas Medicinais 9: 102107.

Hare, R.C. 1978. Effect of shoot girdling and season on rooting of slash pine cuttings. Canadian Journal of Forest Research 8:14-16.

Hartmann, H.T., Kester, D.E., Davies JR, F.T., Geneve, R.L. 2011. Hartmann \& Kerster's plant propagation: principles and practices. Prentice Hall, New Jersey, USA. 915 p.

Ju, J.B., Kim, J.S., Choi, C.W., Lee, H.K., Oh, T.K., Kim, S.C. 2008. Comparison between ethanolic and aqueous extracts from Chinese juniper berries for hypoglycaemic and hypolipidemic effects in alloxan-induced diabetic rats. Journal of Ethnopharmacology 115:110-115.

Khoushnevis, M., Ali Ahmad Koruri, S., Teymouri, M., Matinizadeh, M., Rahmani, A., Shirvani, A. 2008. The effect of different treatments on rooting of Juniperus excels cutting. Iranian Journal of Forest and Poplar Research 16:158-167.

Kibbler, H., Johnston, M.E., Williams, R.R. 2004. Adventitious root formation in cuttings of Backhousia citriodora F. Muell: 2. Seasonal influences of temperature, rainfall, flowering and auxins on the stock plant. Scientia Horticulturae 102: 343-358.

Kunneman, B.P.A.M., Ruesink, J.B. 1997. Interactions between light, temperature and $\mathrm{CO} 2$ in rooting of conifer cuttings. Acta Horticulturae 418: 97-102.

Lawson, T., Kramer, D.M., Raines, C.A. 2012. Improving yield by exploiting mechanisms underlying natural variation of photosynthesis. Current Opinion in Biotechnology 23: 215-220.

Lorenzi, H. 2003. Árvores exóticas no Brasil: madeireiras, ornamentais e aromáticas. Instituto Plantarum, Nova Odessa, Brasil. 368 p.

Maia, S.S., Pinto, J.E., Silva, F.N., Oliveira, C. 2008. Enraizamento de Hyptis suaveolens (L.) Poit. (Lamiaceae) em função da posição da estaca no ramo. Brazilian Journal of Agricultural Sciences
3: $317-320$.

Marangon, M.A., Biasi, L. A. 2013. Estaquia de mirtilo nas estações do ano com ácido indolbutírico e aquecimento do substrato. Pesquisa Agropecuária Brasileira 48: 25-32.

Negash, L. 2002. Successful vegetative propagation techniques for the threatened African pencil cedar. Forest Ecology and Management 161:53-64.

Oliveira, M.C., Ribeiro, J.F. 2013. Enraizamento de estacas de Euplassa inaequalis (Pohl) Engl. de mata de galeria em diferentes estações do ano. Bioscience Journal 29: 991-999.

Osterc, G., Štampar, F. 2011 . Differences in endo/ exogenous auxin profile in cuttings of different physiological ages. Journal of Plant Physiology 168: 2088-2092.

Paula, L.A., Corrêa, L.S., Boliani, A.C., Santos, P.C. 2009. Efeito do ácido indolbutírico e épocas de estaqueamento sobre o enraizamento de estacas herbáceas de figueira (Ficus carica L.). Acta Scientiarum Agronomy 31: 87-92.

Pop, T.I., Pamfil, D., Bellini, C. 2011 . Auxin Control in the Formation of Adventitious Roots. Notulae Botanicae. Horti Agrobotanici Cluj-Napoca 39: 307-316.

Ragonezi, C., Klimaszewska, K., Castro, M.R., Lima, M., Oliveira, P., Zavattieri, M.A. 2010. Adventitious rooting of conifers: influence of physical and chemical factors. Trees 24: 975-992.

Stuepp, C.A., Pereira, G.P., Zem, L.M., Peña, M.L.P., Bueno, P. M.C., Spader, V., Zuffellato-Ribas, K.C., Rosa, G.M. 2013. Enraizamento de melaleuca: influência da altura de coleta das estacas e aplicação de iba. Colloquium Agrariae 9: 01-09.

Stuepp, C.A., Zuffellato-Ribas, K.C., Macanhão, G., Fragoso, R.O., Rickli, H.C. 2014. Estaquia caulinar de Juniperus chinensis var. kaizuka: concentrações de IBA e diferentes alturas de coleta. Agrarian 7: 496-503.

Tehranifar, A., Tabar, S.M., Selahvarzi, Y., Balandary, A., Kharrazi, M. 2014. Biochemical changes in barberries during adventitious root formation: the role of indole-3-butyric acid and hydrogen peroxide. Spanish Journal of Agricultural Research 12: 477-485.

Trevisan, R., Franzon, R. C., Fritsche Neto, R., Gonçalves, R. S., Gonçalves, E. D., Antunes, L. E. C. 2008. Enraizamento de estacas herbáceas de mirtilo: influência da lesão na base e do ácido indolbutírico. Ciência e Agrotecnologia 32: 402-406.

Wendling, I., Trueman, S.J., Xavier, A. 2014 a. 
Maturation and related aspects in clonal forestry - Part I: concepts, regulation and consequences of phase change. New Forest 45:449-471.

Wendling, I., Trueman, S.J., Xavier, A. 2014b. Maturation and related aspects in clonal forestry-part II: reinvigoration, rejuvenation and juvenility maintenance. New Forests 45: 473-486. 